\title{
Potential latitudinal variation in orodigestive tract cancers in Africa
}

\author{
H A Adeola, ${ }^{1,2} \mathrm{BDS}, \mathrm{PhD}(\mathrm{Med}) ; \mathrm{A}$ O Adefuye, ${ }^{3} \mathrm{MB} \mathrm{ChB}, \mathrm{PhD}(\mathrm{Med}) ; \mathbf{S}$ A Jimoh, ${ }^{4} \mathrm{BSc}, \mathrm{PhD}(\mathrm{Med})$ \\ ${ }^{1}$ Department of Oral and Maxillofacial Pathology, Faculty of Dentistry, University of the Western Cape and Tygerberg Hospital, Cape Town, South Africa \\ ${ }^{2}$ Division of Dermatology, Department of Medicine, Faculty of Health Sciences and Groote Schuur Hospital, University of Cape Town, South Africa \\ ${ }^{3}$ Division Health Sciences Education, Office of the Dean, Faculty of Health Sciences, University of the Free State, Bloemfontein, South Africa \\ ${ }^{4}$ Department of Anatomical Sciences, Faculty of Health Sciences, Walter Sisulu University, Mthatha, Eastern Cape, South Africa
}

Corresponding author: H A Adeola (henry.adeola@uct.ac.za)

Background. Previous studies have alluded to a causal relationship between pathological entities and geographical variations, but there is a paucity of studies from Africa discussing the effect of latitudinal variation on orodigestive cancers in this region. It seems plausible that the burden of orodigestive cancer would differ as a result of variations in diet, cultural habits, climate and environmental conditions down the length of Africa.

Objectives. To analyse regional variations in prevalence, incidence and mortality data in the global cancer statistics database (GLOBOCAN 2012) curated by the World Health Organization and the International Agency for Research on Cancer. Basic descriptive statistical tools were used to depict regional variations in cancer morbidity and mortality.

Methods. Data on 13 African countries between longitude $20^{\circ}$ and $30^{\circ}$ east and latitude $35^{\circ}$ north and $35^{\circ}$ south were examined for variation in age-standardised orodigestive cancer prevalence, incidence and mortality. Possible regional causes for orodigestive tract cancer development were investigated. Data on lip and oral cavity, oesophageal, gastric, colorectal, liver, gallbladder and pancreatic cancers in the 13 countries were compared.

Results. Our empirical findings from this preliminary study support the notion that the incidence and prevalence of orodigestive cancers vary within Africa. This effect may be due to environmental, economic, political and possibly genetic factors.

Conclusions. Considering the heterogeneity of the above factors across Africa, disbursement of funding for cancer research and therapy in Africa should be focused in terms of regional variations to make best use of the fiscal allocation by African governments, non-governmental organisations and international agencies.

S Afr Med J 2018;108(4):347-351. DOI:10.7196/SAMJ.2018.v108i4.12908

Cancer is a major public health problem globally, and gastrointestinal cancers are common. ${ }^{[1]}$ Furthermore, cancer mortality is relatively high in black people owing to factors such as population-specific high incidences of cancer, late stage at diagnosis and poor survival profiles. ${ }^{[2]}$ There is evidence of disparity in terms of age, sex and race in the survival profile of gastrointestinal cancer cases from nine population-based cancer registries in the Surveillance, Epidemiology, and End Results programme of the National Cancer Institute. ${ }^{[1]}$ In this study it was found, for example, that Caucasians with anal and small-intestinal cancer had better survival rates than African Americans. ${ }^{[1]}$ Cordice and Johnson ${ }^{[3]}$ demonstrated that African Americans had relatively more proximal colonic tumours than the general population. ${ }^{[3]}$ Although some progress has been made in reducing cancer deaths in African American populations, their 5-year relative survival is lower than that of Caucasians for many cancers at every stage of diagnosis. ${ }^{[4]}$

It is hypothesised that primitive ocean dwellers underwent homeostatic evolution into terrestrial creatures, carrying with them interstitial fluid resembling the salt solution of the very seas from which they came. ${ }^{[5]}$ However, in physicochemical terms, terrestrial environments are far more variable than the aquatic environment. Terrestrial animals have established a complex biochemical dependence on their external surroundings. ${ }^{[6]}$ In essence, the health of terrestrial animals in a habitat, including humans, is directly influenced by the environment. There is ample evidence that environmental factors play a central role in the development of cancer in migrant populations, and that their cancer risk in their native homeland and that in the countries to which they have emigrated can differ. ${ }^{[7]}$ Although there is a dearth of research-based data for meaningful evaluation of regional gastrointestinal cancer disparities in Africa, the GLOBOCAN database provides the most comprehensive information for international comparison of cancer incidence, mortality and prevalence. ${ }^{[8]}$ Further research is needed to establish evidence-based regional disparities in cancer in Africa. For example, Atoba et al. ${ }^{[9]}$ found an overall poor prognosis in a cohort of 695 patients with gastroenterological malignancies in tropical Africa. ${ }^{[9]}$

The large muscular tube that goes from the mouth to the anus, including the oesophagus, stomach and intestines, and is involved in the digestion of food and elimination of waste products, is known as the orodigestive tract (ODT) or alimentary canal. The embryological primordium for the ODT is the primitive gut tube, which is believed to arise from the definitive endoderm during the late gastrula stage. ${ }^{[10]}$ Most of its lining is variably covered with epithelial cells that are sometimes functionally modified. ${ }^{[1]}$ Dietary carcinogens gain access to the ODT via the mouth, ${ }^{[12]}$ which in humans serves as one of the gateways for sampling the external environment.

It is possible that latitude may affect the development of cancer, since latitudinal variation correlates with changes in solar exposure and geography. A latitudinal relationship has been found between the typical diet in the Mediterranean region (high olive oil consumption) 
and a low risk of development of myocardial infarction. ${ }^{[13]}$ Effects of geographical latitude have also been reported for schizophrenia, neural tube defects, and prostate, breast and other cancers. ${ }^{[14-18]}$ This effect of latitude on various disease incidences has been found to increase with increasing distance from the Equator in both the Northern and Southern hemispheres. ${ }^{[13]}$

Variations in temperature from the Equator to the poles would, by extension, determine the soil content/texture and atmospheric content of the environment. Differences in food and other environmental carcinogen exposure along the north-tosouth geographical gradient in Africa may contribute to a greater or lesser extent to ODT cancer development. It has been reported that genetic or hereditary predisposition only plays a minor role in cancer development, ${ }^{[19]}$ while environmental exposure plays a more pivotal role. ${ }^{[19]}$ An important point is that the risk of developing cancer is highly associated with the environment into which an individual migrates, rather than their country of origin. ${ }^{[7,19]}$ Epigenetic and genetic factors have been shown to influence the risk of development of ODT cancers, and these emerging molecular findings are poised to serve as a basis for targeted ODT cancer therapies.

Molecular embryology of the gut tube development has shown a spatially regulated regionalisation of homeobox-containing transcription factors. For instance, Hoxa 3 and Hoxb4 were found to be specifically expressed in the foregut, while Hoxc5 and Hoxa13 were found to be more expressed in the midgut and hindgut, respectively. ${ }^{[20]}$ Sonic hedgehog $(\mathrm{SHH})$ has been found expressed throughout the gut tube, with the exception of pancreatic tissue. ${ }^{[21]}$ Further, the molecular pathways controlling the anteriorposterior, dorsal-ventral, left-right and radial gut axis have become a hot topic in ODT development. ${ }^{[22]}$ Such regional variation in molecular signature can serve as a basis for diagnostic and therapeutic approaches. The development and homeostasis of the ODT has been shown to depend on hormonal mechanisms, ${ }^{[23]}$ genetic mutations in neural crest cell migration, ${ }^{[24]}$ alcohol consumption, ${ }^{[25]}$ chronic inflammation, ${ }^{[26]}$ mucosa-associated microbiota, ${ }^{[27]}$ stem cell niches, ${ }^{[28]}$ gut epithelial barriers ${ }^{[29]}$ and intestinal permeability. ${ }^{[30]}$ Changes in the degree of keratinisation or the keratinisation status of ODT epithelial tissue due to chemical irritants and chronic trauma are widely reported. ${ }^{[11,31,32]}$ Dysregulation of keratin genes in dysplastic oral epithelial cells and cancer has also been described. ${ }^{[33]}$
Type of diet, oral hygiene status and environmental factors have been suggested as possible factors implicated in the development of several histological variants of ODT cancers. ${ }^{[34]}$ Potentially malignant inflammatory bowel diseases have been suspected to be caused by particulate matters ingested from the environment. ${ }^{[35]}$ Helicobacter pylori and Escherichia coli have been implicated in the pathogenesis of gastric and colon cancer, respectively. ${ }^{[36,37]}$ The gut microbiota is now emerging as a key determinant of health status, ${ }^{[38]}$ which is sometimes largely determined by pathogens ingested (with food) from the environment. Consumption of homebrewed African beer (uMqombhothi) made from fermenting (often fungus-infected) maize or sorghum in various parts of South Africa (SA) has been implicated in the high incidence of oesophageal cancer in these regions. ${ }^{[39,40]}$ It has been suggested that the change from sorghum to maize as a dietary staple was responsible for the spike in oesophageal cancer among blacks in SA. ${ }^{[41]}$ Clearly, carcinogenesis in the gut is affected by dietary, infection exposure and environmental differences that would be expected in different latitudes in Africa. In this preliminary study, we examined the potential variations in ODT cancer based on geographical latitude on the continent.

\section{Methods}

\section{Country selection}

Countries were specifically selected from the longest block in the mid-portion of the map of Africa (Fig. 1). These regions correspond to African countries between longitude $20^{\circ}$ and $30^{\circ}$ east. Thirteen countries with good alignment with these co-ordinates were considered. From north to south, the selected countries were Libya, Egypt, Chad, Sudan, Central African Republic, South Sudan, Rwanda, Democratic Republic of the Congo (DRC), Angola, Zambia, Zimbabwe, Botswana and SA. All 13 selected countries fall between latitude $35^{\circ}$ north and $35^{\circ}$ south. Countries that do not fall in good alignment with these co-ordinates were excluded. These 13 countries were used to analyse variations in gastrointestinal cancer at different latitudes in Africa.

\section{GLOBOCAN database information}

We reviewed secondary data archived by the World Health Organization and the International Agency for Research on Cancer in GLOBOCAN 2012 global cancer statistics. $^{[42]}$ The GLOBOCAN database provides updates on major cancer types, incidences, prevalences and mortality rates for 184 nations of the world. The estimates are presented for men, women and both sexes. There is a continual effort to improve the

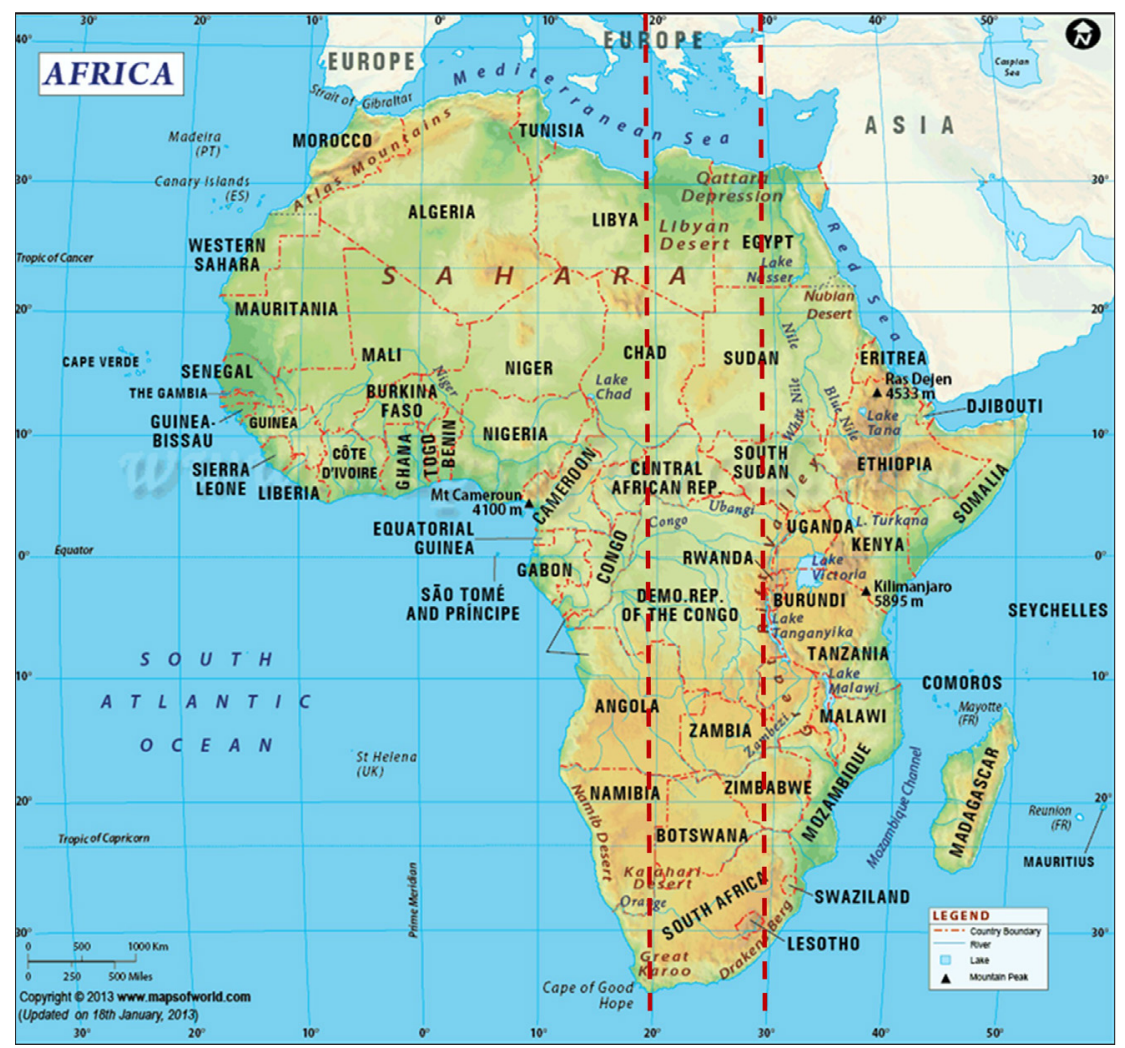

Fig. 1. Geographical region sampled. As shown, countries between longitude $20^{\circ}$ and $30^{\circ}$ east were sampled (red broken vertical lines) from about $35^{\circ}$ north to $35^{\circ}$ south (adapted from www.mapsofworld.com). 
quality of data and coverage, although figures may not remain the same over a prolonged period, resulting in differences in data every time the database is updated. Potential methodological differences between updates mean that the database may therefore not be ideal for making statistical inferences over a period of time. Data are derived from national and regional sources using percentage coverage, rates and frequencies. The mode of estimation is country-specific, and the quality of data depends on the quality of information available locally; estimates are made where local sources are inadequate. Country-specific summaries of burden of disease of any major type of cancer can be accessed using the 'fact sheet' option. Typically, this option generates basic statistical summaries on the eight most common cancers as well as regional and country-specific data. In addition, simple online analysis can be performed to generate additional visualisation such as maps and bar graphs using the 'online analysis' option.

\section{Cancer selection criteria}

All ODT cancers documented in the GLOBOCAN 2012 data repository, including cancers of main and accessory digestive organs, were studied. Seven of the included regions were selected, viz. lip and oral cavity (LOC), oesophagus, stomach, liver, gallbladder, pancreas and colorectum. Malignancies involving the pharyngeal regions were not included, because only the oropharynx is directly involved with the digestive tract anatomically. Oropharyngeal lesions were not described separately in the GLOBOCAN databases. Other pharyngeal regions including the nasopharynx and laryngopharynx would be more appropriately discussed under respiratory cancers.

\section{Comparative analysis}

Data on age-standardised rates (ASRs) for incidence, mortality and prevalence were collected for the 13 countries selected. Histograms for ASRs for incidence, mortality and prevalence were plotted and compared for males and females in the selected countries, and north-to-south trends in ASR variations were visualised.

\section{Results and discussion}

Analyses of the GLOBOCAN data for the selected geographical regions showed that the incidence, prevalence and mortality rates of LOC cancer in men were lower in the northern countries and towards the southern countries, with high peaks in the central African countries (Fig. 2, A). The incidence and prevalence trends of LOC cancers were highest among men in Botswana and SA, although the peaks for mortality in these countries were lower, probably reflecting quality of healthcare services. The incidence trend of LOC cancers from north to south for females appears generally heterogeneous and flat. This trend was similar for LOC cancer prevalence in females, with a dip in the Republic of Congo. Mortality rates were found to be lower in the northern and southern countries, with higher peaks in central African countries.

For both sexes the ASR for oesophageal cancer incidence, prevalence and mortality showed an increasing trend from north to south (Fig. 2, B). However, age-standardised incidence, prevalence and mortality were higher for men than for women in the selected countries. ASRs in Sudan, Rwanda and South Sudan were found to have spikes along the trend line, particularly for males. The common habit of placing a paste of tobacco snuff known as toombak mixed with slaked lime and water in the vestibules of the mouth and beneath the tongue and leaving it there for many hours every day has been identified as a risk factor for the high incidence of upper aerodigestive tract cancers in Sudan. ${ }^{[43,44]}$ A geographical survey of sugar-based alcoholic spirits brewed in Central Africa (kachasu) revealed contamination with zinc and carcinogenic nitrosamines, leading to a high incidence of oesophageal cancer in parts of this region. ${ }^{[45]}$

Similarly, a trend for ASRs for gastric cancers to increase from north to south was noted. This was more defined in males than in females (Fig. 2, C). Spikes in ASR trends were found in Egypt and Libya as well as in the centrally located South Sudan, Rwanda and DRC. A dip in all ASR trends for gastric cancers was observed in Botswana for both sexes. In an epidemiological study of the geographical distribution of $H$. pylori in a cohort of Middle Eastern countries, Egypt and Libya were found have a high prevalence

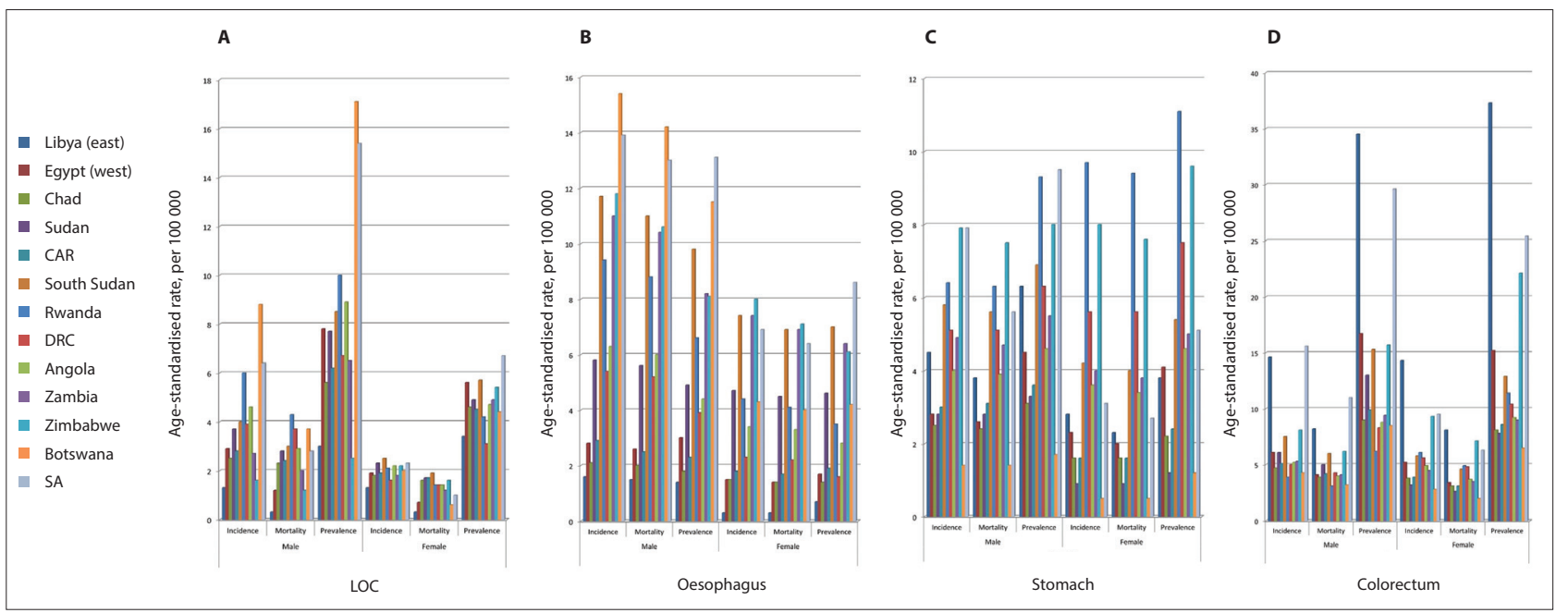

Fig. 2. Bar graphs showing the age-standardised incidence, mortality and prevalence for cancers of the LOC (A), oesophagus (B), stomach (C) and colorectum (D). The graph for LOC cancers shows that the prevalence and mortality in men were lower in the northern and southern countries, with high peaks in the central African countries. For oesophageal cancer, there was an increasing trend for both sexes from north to south, with a spike for men in Sudan, Rwanda, and South Sudan. For stomach cancer there was an increasing trend from north to south, with spikes observed in Egypt and Libya, as well as the centrally located South Sudan, Rwanda and DRC; there was also a dip in the trend in Botswana for both sexes. For colorectal cancer, incidence, prevalence and mortality rates were heterogeneous for males and females, and high figures were found in Libya, Egypt, Zimbabwe and SA. (LOC =lip and oral cavity; CAR = Central African Republic: DRC = Democratic Republic of the Congo; SA = South Africa.) 


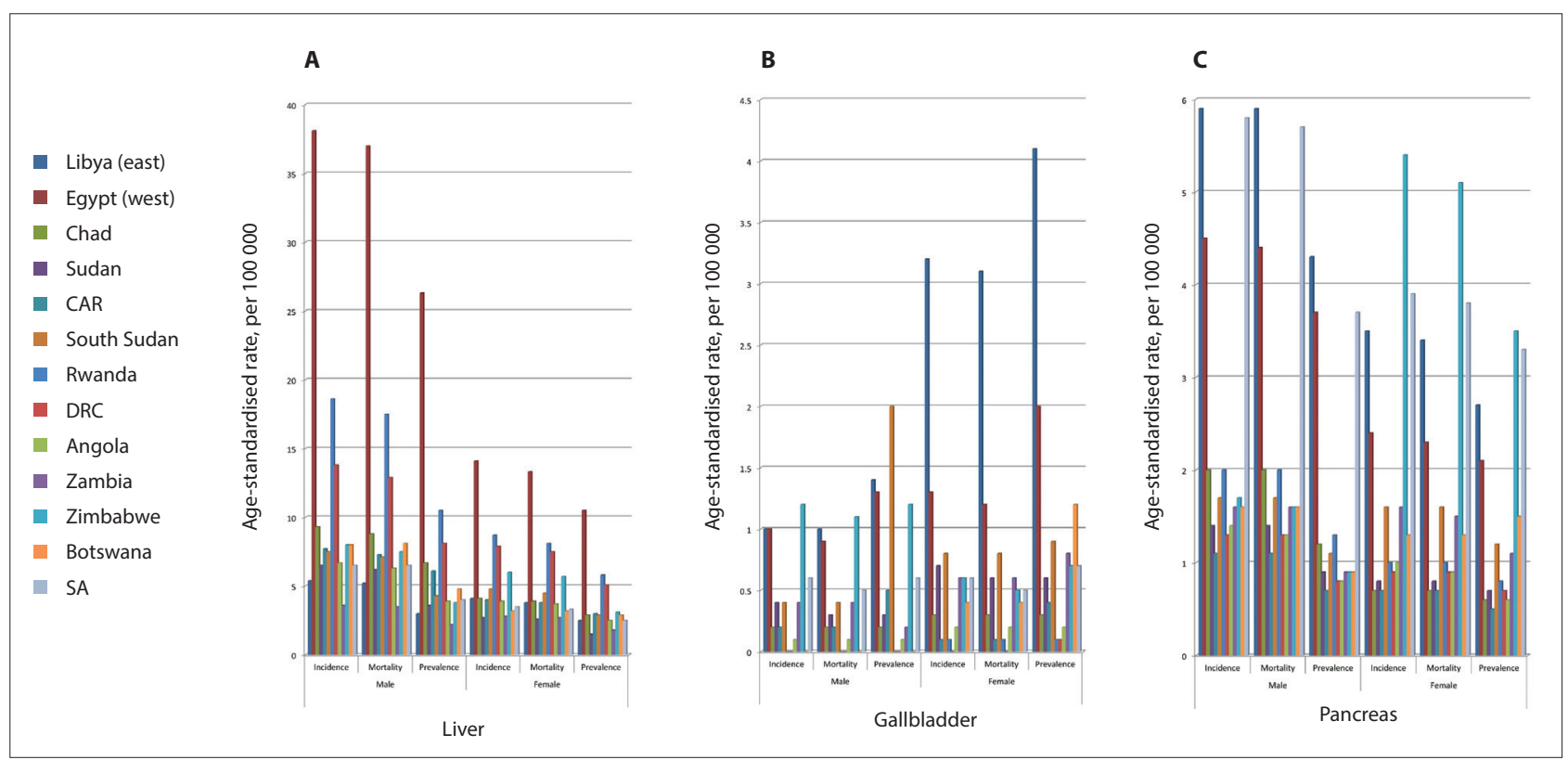

Fig. 3. Bar graphs showing the age-standardised incidence, mortality and prevalence for cancers of the liver (A), gallbladder (B) and pancreas (C). The graph for liver cancer shows a heterogeneous trend for males and females, with notably high spikes in Egypt, Rwanda and DRC. Trends for liver cancer were generally higher in males than in females. The graph for gallbladder cancer also shows a heterogeneous trend, but males appeared to be affected more than females in some countries. Gallbladder cancer rates were found to be higher for females than males in Egypt and Libya. Spikes were also found in Sudan, South Sudan, Zambia, Zimbabwe and SA. The graph for pancreatic cancer also shows a flat trend for both sexes. High spikes were found in Egypt, Libya and SA for both sexes, and in Zimbabwe for females. (CAR = Central African Republic: DRC = Democratic Republic of the Congo; SA = South Africa.)

of $H$. pylori, although gastric cancer rates were found to be lower in Egypt than in Iran. ${ }^{[46]}$ In a review by Asombang and Kelly, ${ }^{[47]}$ a GLOBOCAN-based low incidence in Botswana (0.3/100 000) was used to demonstrate the wide variation in gastric cancer rates in Africa.

The ASRs for colorectal cancer incidence, prevalence and mortality for the selected countries were heterogeneous for both males and females. However, high figures were observed in Libya and Egypt, and moving southwards in Zimbabwe and SA (Fig. 2, D). Egypt has been reported to have a high incidence of early-onset colorectal cancer, possibly owing to dietary patters in the lower age groups ${ }^{[48]}$ while Libya has been reported to have the highest rate of colorectal cancer in northern Africa. ${ }^{[49]}$ Demographics may play a role in the high incidence of colorectal cancer in Zimbabwe and SA, as these two southern African countries have a sizeable Caucasian population.

All ASR trends for liver cancer were also heterogeneous for males and females, with rates in Egypt, Rwanda and DRC notably high. Incidence and mortality trends were generally higher in males than in females (Fig. 3, A). Egypt has one of the highest incidences of hepatitis $\mathrm{C}$ virus in the world, accounting for the high incidence of primary liver cancer. ${ }^{[50-52]}$ Consumption of grains contaminated with aflatoxin $\mathrm{B} 1$ and chronic alcohol consumption are other known risk factors for primary liver disease. ${ }^{[52]}$ Liver cancer rates were reported to be high in Rwanda and DRC, possibly owing to chronic hepatitis $B$ and $\mathrm{C}$ infection. ${ }^{[53]}$

No clear-cut ASR trends were found for gallbladder cancer, but it does seem to affect more females than males in the selected countries (Fig. 3, B). All ASRs for gallbladder cancer were high in Egypt and Libya, particularly for females, and spikes were found in Sudan, South Sudan, Zambia, Zimbabwe and SA. The high prevalence of gallbladder cancer in Egypt and Libya may be shadowing the liver cancer trends, since the gallbladder is an accessory organ of the hepatobiliary system.
Pancreatic cancer demonstrated a flat trend both for males and females in the selected countries from north to south (Fig. 3, C). High ASRs for incidence, prevalence and mortality were reported for Egypt, Libya and SA in both sexes, and for Zimbabwe in females. Primary malignant lesions affecting the pancreas, another organ that is part of the hepatobiliary tract, seem to be concentrated in urban settings along the north-south trajectory.

\section{Conclusions}

This is a preliminary study demonstrating that diseases indeed vary according to latitude, particularly in Africa, where there is wide geographical, economic, genetic and political variation between countries. A major shortcoming of this study is that estimates were used for countries without cancer registry data, which may skew inferences. The trends observed may reflect availability of national cancer registries and not necessarily high burdens. However, the trends warrant further investigation, as they could potentially guide the distribution of cancer spending across Africa.

\section{Acknowledgements. None.}

Author contributions. HAA conceptualised, designed, prepared and critically revised the manuscript and figures. AOA and SAJ were involved in the design and critical intellectual revision of the paper. All authors were involved in data collection and analysis, and manuscript preparation. Funding. HAA thanks the South African Medical Research Council for a mid-career scientist research fellowship.

Conflicts of interest. None.

\footnotetext{
1. Wan JF, Yang LF, Shen YZ, et al. Sex, race, and age disparities in the improvement of survival for gastrointestinal cancer over time. Sci Rep 2016;6:29655. https://doi.org/10.1038\%2Fsrep29655 2. Boring CC, Squires TS, Health CW Jr. Cancer statistics for African Americans. CA Cancer J Clin 1992;42(1):7-17. https://doi.org/10.3322/canjclin.42.1.7

3. Cordice JW Jr, Johnson H Jr. Anatomic distribution of colonic cancers in middle-class black Americans. J Natl Med Assoc 1991;83(8):730-732.
} 
4. DeSantis C, Naishadham D, Jemal A. Cancer statistics for African Americans, 2013. CA Cancer J Clin 2013;63(3):151-166. https://doi.org/10.3322/caac.21173

5. Gross CG. Claude Bernard and the constancy of the internal environment. Neuroscientist 1998;4(5):380-385. https://doi.org/10.1177/107385849800400520

6. Dissanayake C. Global Voices of Science. Of stones and health: Medical geology in Sri Lanka. Science 2005;309(5736):883-885. https://doi.org/10.1126/science.1115174

7. Boyd J, Langman M, Doll R. The epidemiology of gastrointestinal cancer with special reference to causation. Gut 1964;5(2):196-200

8. Asombang AW, Rahman R, Ibdah JA. Gastric cancer in Africa: Current management and outcomes. World J Gastroenterol 2014;20(14):3875-3879. https://doi.org/10.3748\%2Fwjg.v20.i14.3875

9. Atoba MA, Olubuyide IO, Aghadiuno PO. Gastrointestinal malignancies in a young tropical African population. Trop Doct 1989;19(3):135-137. https://doi.org/10.1177/004947558901900314

10. San Roman AK, Shivdasani RA. Boundaries, junctions and transitions in the gastrointestinal tract. Exp Cell Res 2011;317(19):2711-2718. https://doi.org/10.1016/j.yexcr.2011.07.011

11. McLean WH, Irvine AD. Disorders of keratinisation: From rare to common genetic diseases of skin and other epithelial tissues. Ulster Med J 2007;76(2):72-82.

12. Abnet CC. Carcinogenic food contaminants. Cancer Invest 2007;25(3):189-196. https://doi. org/10.1080\%2F07357900701208733

13. Jongbloet PH. Is the Mediterranean diet relevant to myocardial infarction? Olive oil consumption versus geographical latitude. Int J Epidemiol 2003;32(5):878-879. https://doi.org/10.1093/ije/dyg242

14. Munan L, Kelly A. Frequency of fatal congenital anomalies of the nervous system: Association with Munan L, Kelly A. Frequency of fatal congenital anomalies of the nervous system: Association with
geographic latitude. Soc Biol 1979;26(4):335-340. https://doi.org/10.1080/19485565.1979.9988391

geographic latitude. Soc Biol 1979;26(4):335-340. https://doi.org/10.1080/19485565.1979.9988391
15. Gupta S, Murray RM. The relationship of environmental-temperature to the incidence and outcome of 5. Gupta S, Murray RM. The relationship of environ
schizophrenia. Br J Psychiatry 1992;160:788-792.

16. Hanchette CL, Schwartz GG. Geographic patterns of prostate-cancer mortality - evidence for a protective effect of ultraviolet-radiation. Cancer 1992;70(12):2861-2869. https://doi.org/10.1002/1097 0142(19921215)70:12<2861::AID-CNCR2820701224>3.0.CO;2-G

17. Gorham ED, Garland FC, Garland CF. Sunlight and breast-cancer incidence in the USSR. Int J Epidemiol 1990;19(4):820-824

18. Facchini U, Camnasio M, Cantaboni A, Decarli A, Lavecchia C. Geographical variation of cancer mortality in Italy. Int J Epidemiol 1985;14(4):538-548. https://doi.org/10.1093/ije/14.4.538

19. Anand $P$, Kunnumakkara AB, Sundaram $C$, et al. Cancer is a preventable disease that requires major lifestyle changes. Pharm Res 2008;25(9):2097-2116. https://doi.org/10.1007\%2Fs1 1095-008-9661-9

20. Faure S, Barbara PD. Molecular embryology of the foregut. J Pediatr Gastr Nutr 2011;52:S2-S3. https:// doi.org/10.1097/MPG.0b013e3182105ala

21. Roberts DJ, Johnson RL, Burke AC, Nelson CE, Morgan BA, Tabin C. Sonic hedgehog is an endodermal signal inducing Bmp-4 and Hox genes during induction and regionalization of the chick hindgut. Development 1995:121(10):3163-3174

22. Roberts DJ. Molecular mechanisms of development of the gastrointestinal tract. Dev Dynam 2000;219(2):109120. https://doi.org/10.1002/1097-0177(2000)9999:9999\%3C::AID-DVDY1047\%3E3.0.CO;2-6

23. Menard D. Functional development of the human gastrointestinal tract: Hormone- and growth factormediated regulatory mechanisms. Can J Gastroenterol 2004;18(1):39-44.

24. Montgomery RK, Mulberg AE, Grand RJ. Development of the human gastrointestinal tract: Twenty years of progress. Gastroenterology 1999;116(3):702-731.

25. Nazer H, Wright RA. The effect of alcohol on the human alimentary tract: A review. J Clin Gastroenterol 1983;5(4):361-365

26. De Lerma Barbaro A, Perletti G, Bonapace IM, Monti E. Inflammatory cues acting on the adult intestinal stem cells and the early onset of cancer (Review). Int J Oncol 2014;45(3):959-968. https:// doi.org/10.3892\%2Fijo.2014.2490

27. Rausch P, Rehman A, Kunzel S, et al. Colonic mucosa-associated microbiota is influenced by an interaction of Crohn disease and FUT2 (Secretor) genotype. Proc Natl Acad Sci U S A by an interaction of Crohn disease and FUT2 (Secretor) genoty

28. Van der Wath RC, Gardiner BS, Burgess AW, Smith DW. Cell organisation in the colonic crypt: A theoretical comparison of the pedigree and niche concepts. PLoS One 2013;8(9). https://doi. org/10.1371\%2Fjournal.pone.007320

29. Pastorelli L, de Salvo C, Mercado JR, Vecchi M, Pizarro TT. Central role of the gut epithelial barrier in the pathogenesis of chronic intestinal inflammation: Lessons learned from animal models and human genetics. Front Immunol 2013;4(280):1-22. https://doi.org/10.3389/fimmu.2013.00280
30. Bischoff SC, Barbara G, Buurman W, et al. Intestinal permeability - a new target for disease prevention and therapy. BMC Gastroenterol 2014;14:189. https://doi.org/10.1186/s12876-014-0189-7

31. Shetty S, Gokul S. Keratinization and its disorders. Oman Med J 2012;27(5):348-357. https://doi. org $/ 10.5001 \% 2$ Fomj. 2012.90

32. Woo SB, Lin D. Morsicatio mucosae oris - a chronic oral frictional keratosis, not a leukoplakia. J Oral Maxillofac Surg 2009;67(1):140-146. https://doi.org/10.1016/.j.joms.2008.08.040

33. Mikami T, Cheng J, Maruyama S, et al. Emergence of keratin 17 vs. loss of keratin 13: Their reciprocal immunohistochemical profiles in oral carcinoma in situ. Oral Oncol 2011;47(6):497-503. https://doi. org/10.1016/j.oraloncology.2011.03.015

34. Wenig BM. Squamous cell carcinoma of the upper aerodigestive tract: Precursors and problematic variants. Mod Pathol 2002;15(3):229-254. https://doi.org/10.1038/modpathol.3880520

35. Beamish LA, Osornio-Vargas AR, Wine E. Air pollution: An environmental factor contributing to intestinal disease. J Crohns Colitis 2011;5(4):279-286. https://doi.org/10.1016/j.crohns.2011.02.017

36. Bonnet $\mathrm{M}$, Buc E, Sauvanet $\mathrm{P}$, et al. Colonization of the human gut by E. coli and colorectal cancer risk Clin Cancer Res 2014;20(4):859-867. https://doi.org/10.1158/1078-0432.CCR-13-1343

37. De Koster E, Buset M, Fernandes E, Deltenre M. Helicobacter pylori: The link with gastric cancer. Eur J Cancer Prev 1994;3(3):247-257.

38. Rajendhran J, Gunasekaran P. Human microbiomics. Indian J Microbiol 2010;50(1):109-112. https:/ doi.org/10.1007\%2Fs12088-010-0034-9

39. Dlamini Z, Bhoola K. Esophageal cancer in African blacks of Kwazulu Natal, South Africa: An epidemiological brief. Ethn Dis 2005;15(4):786-789.

40. Segal I, Reinach SG, de Beer M. Factors associated with oesophageal cancer in Soweto, South Africa. Br J Cancer 1988;58(5):681-686.

41. Isaacson C. The change of the staple diet of black South Africans from sorghum to maize (corn) is the cause of the epidemic of squamous carcinoma of the oesophagus. Med Hypoth 2005;64(3):658-660 https://doi.org/10.1016/j.mehy.2004.09.019

42. Ferlay J, Soerjomataram I, Dikshit R, et al. Cancer incidence and mortality worldwide: Sources, methods and major patterns in GLOBOCAN 2012. Int J Cancer 2015;136(5):E359-E386. https://doi. org/10.1002/ijc.29210

43. Idris AM, Prokopczyk B, Hoffmann D. Toombak: A major risk factor for cancer of the oral cavity in Sudan. Prev Med 1994;23(6):832-839. https://doi.org/10.1006/pmed.1994.1141

44. Boulos PB, El Masri SH. Carcinoma of the oesophagus in the Sudan. Trop Geogr Med 1977;29(2):150-154

45. McGlashan ND. Oesophageal cancer and alcoholic spirits in central Africa. Gut 1969;10(8):643-650.

46. Hussein NR. Helicobacter pylori and gastric cancer in the Middle East: A new enigma? World Hussein NR. Helicobacter pylori and gastric cancer in the Middle East: A new
Gastroenterol 2010;16(26):3226-3234. https://doi.org/10.3748\%2Fwig.v16.i26.3226

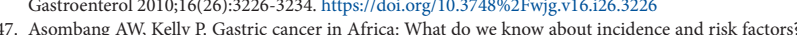
Trans R Soc Trop Med Hyg 2012;106(2):69-74. https://doi.org/10.1016/j.trstmh.2011.11.002
The

48. Soliman AS, Levin B, Khorshid A, Ibrahim N, Dorgham L, McPherson RS. Diet and cooking practices in Egypt: Potential relationship to early-onset colorectal cancer. FASEB J 1998;12(4):A222-A. https:/ doi.org/10.1016/S0271-5317(98)00064-5

49. Bodalal Z, Bendardaf R. Colorectal carcinoma in a Southern Mediterranean country: The Libya scenario. World J Gastrointest Oncol 2014;6(4):98-103. https://doi.org/10.4251\%2Fwgo.v6.i4.98

50. Soliman AS, Hung CW, Tsodikov A, et al. Epidemiologic risk factors of hepatocellular carcinoma in a rural region of Egypt. Hepatol Int 2010;4(4):681-690. https://doi.org/10.1007/s12072-010-9187-I

51. Omar A, Abou-Alfa GK, Khairy A, Omar H. Risk factors for developing hepatocellular carcinoma in Egypt. Chin Clin Oncol 2013;2(4):43. https://doi.org/10.3978/j.issn.2304-3865.2013.11.07

52. Center MM, Jemal A. International trends in liver cancer incidence rates. Cancer Epidemiol Biomarkers Prev 2011;20(11):2362-2368. https://doi.org/10.1158/1055-9965.EPI-11-0643

53. Sitas F, Parkin M, Chirenje Z, Stein L, Mqoqi N, Wabinga H. Cancers. In: Jamison DT, Feachem RG Makgoba MW, et al., eds. Disease and Mortality in Sub-Saharan Africa. 2nd ed. Washington, DC: Makgoba MW, et al., eds. Disease and Mortality in Sub-Saharan Africa. 2nd ed. Washington, DC nih.gov/books/NBK2279/ (accessed 5 March 2018).

Accepted 6 December 2017 